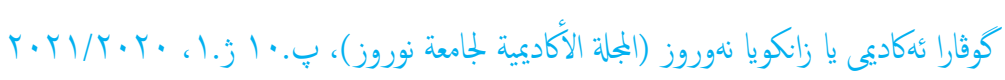

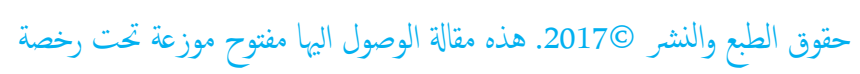

AJ NU

e-ISSN: 2520-789X ،CC BY-NC-ND 4. 0.

https://doi.org/10.25007/ajnu.v10n1a1158

\title{
المعوقات التي تواجه تدريسي كلية العلوم في أثناء كتابة وتطبيق بحوثهم العلمية من وجمة نظر الاساتذة المساعدين والمدرسين
}

م. م بريفان محمد عمر ، قسم التاريخ، كلية التربية الأساسية - جامعة دهوك، كردستان العراق

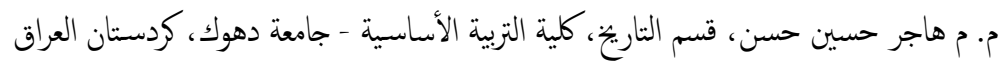

مهدف البحث الحلالي إلى الثعرف على المعوقات التي تواجه تدريسي كلية العلوم في أثناء كتابة وتطبيق بحثمه العلمية من وبجة نظر الاساتذة المساعدين والمدرسين, شملت عينة البحث (40) مدرس واستاذ مساعد بواقع (20) مدرس و(20) أستاذ مساعد من كلة العلوم الدراسات الصباحية جامعة دهوك, ولتحقيق هدف البحث تم إعداد استبانة تكونت من (25) فترة ولكل فقرة ثلاث بدائل

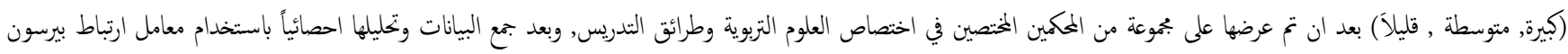
واختخبار التائي لعينتين مستقلتين (t.test), توصلت الباحثة الى النتأُج التالية:

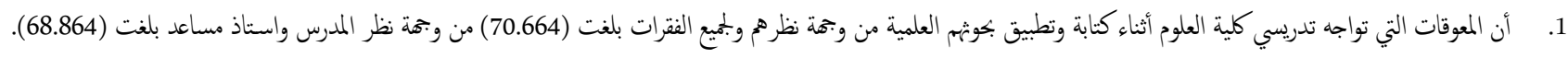

$$
\begin{aligned}
& \text { 2. }
\end{aligned}
$$

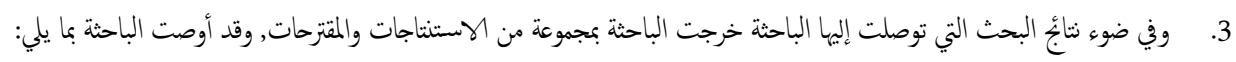

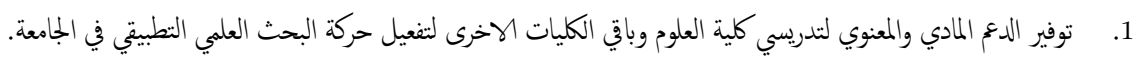

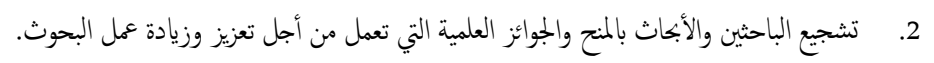

$$
\begin{aligned}
& \text { 3. توفير ميزانية خاصة للبحث العلمي التطبيقي وتسهيل التسويات المالية والإجراءات الإدارية لإجراء البحوث العلمية التطبيقية. } \\
& \text { 4. ت ت توفير الأهزة العلمية المتطورة والكتب والدوريات والأبحاث في المراكز البحثية. } \\
& \text { الكلمات المثتاحية: المعوقات, تدريسي كلية العلوم, البحوث العلمية التطبيقة, الاساتذة المساعدين, المدرسين. }
\end{aligned}
$$

1 1

لذا يعد البحث العلمي التطبيقي الأداة الأساسية والوسيلة لتحقيق التنمية في المجتع وزيادة الانتاج ورفاهية الشعوب والعمل على تراك المعرفة العلمية. وان البحث العلمي التطبيقي من الوسائل التي تساعد في تطوير وكفاءة تدريسي كلية

العلوم من أجل مساعدتهم على مواكبة التطور العلمي الجديد والمعاصر. في حين نجد في جامعاتنا ان الاهتمام بالبحث العلمي التطبيقي أصبح محدوداً ودوره قليلاً وسلبي ولم تهتم بالأبحاث العلمية التطبيقية بشكل كافي من خلال توفير وتهيئة الأجواء المناسبة لتنشيط حركة البحث العلمي التطبيقي. كما ان هناك معوقات تعرقل حركة البحث العلمي التطبيقي في المؤسسات الجامعية ومنها كلية العلوم, حيث يواجه تدريسي كلية العلوم معوقات وصعوبات عديدة أثناء كنابة وتطبيق بحوثهم العلمية, منها عدم الاهتمام بالبحث العلمي التطبيقي وعدم توفير الدع المادي والمعنوي,كما ان البحث العلمي التطبيقي اصبح

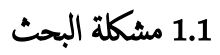

تعتبر الجامعة مؤسسة رئيسية وكمة في الجمتع وإحدى مؤسسات التعليم العالي التي تعمل من أجل تطوير وتنمية الجمتعات ورقيها, كما تعتبر الجامعة المكان الأنسب لاستثمار الطاقات البشرية, وتظهر دور الجامعة في الجمتع في إظهار كوادر وقيادات فعالة, وهذا يعني ان الجمتعات التي تعتمد على الجامعة والأبحاث التي تنجزها مراكز ومؤسسات التعليم العالي تجعلها قادرة على تحتيق التنمية في كافة المجالات الحياتية والتقدم التكنولوجي. يتوقف تطوير الدول على انجازات البحوث العلمية التي تقوم بها مؤسسات التعليم العلي, وان التقدم الحتيقي في الدول لا يتحقق إلا من خلال البحوث الجامعية, والظاهر ان البحث العلمي التطبيقي هو الأساس لنهضة وتطوير الدول المتقدمة

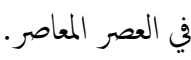




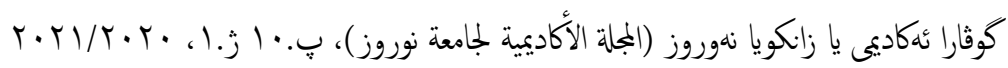

من سات النخلف, ولهذا خصصت الدول المتقدمة ميزانة، لان ذلك يوصلها الى

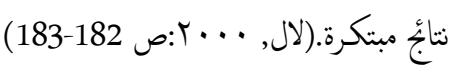
يعد البحث العلمي التطبيقي، احد الوظائف الاساسية للجامعات، فهو مقياس مستواها العلمي, وان الفرد المعني بالدرجة الاولى بالبحث العلمي في الجامعة هو عضو هيأة الندريس الذي يعد مركز الدائرة والطاقة المحركة للمؤسسة الجامعية. (السويدي ع199: ص115), وأصبحت وظيفة التعليم العالي تحقيق التنمية والتطوير داخل الجامعة عن طريق إجراء البحوث العلمية التطبيقية وليس نشر العلم والمعرفة فحسب.(العلي وآخرون,2009:ص 72), وأصبحت الجامعة اليوم

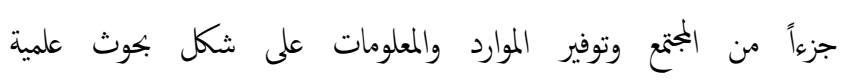

$$
\text { تطبيقة.(الخخلافي,1997: ص2) }
$$

يشكل البحث العلمي التطبيقي رافداً أساسياً تستند عليه الدولة في تقدها, وإذا كانت البحوث العلمية النظرية الاساس في تطور العلم والمعرفة الانسانية, فإن البحوث العلمية التطبيقية هو تجسيد لناك المعرفة على شكل فعل تنموي في تطوير وتحديث الحركة العلمية والنشاطات الاقتصادية ذات العلاقة المباشرة

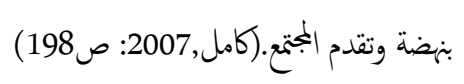

ومن هذا المنطلق تأتي أهمية البحوث العلمية التطبيقة بأهها الدراسة العلمية الموضوعية لإحدى مجالات الطبيعة وعن طريقها يتم اعداد وتدريب الباحثين والمتخصصين على عمليات واساليب البحث العلمي التطبيقي في كافة مجالات الحياة الطبيعة أو دراسة كافة الظواهر الخختلفة ومعالجها وتقديم المعرفة وخبرة واقعية مستمرة وتقديم الحلول التي من شأنها ان تحسن مستويات المعيشية للحياة

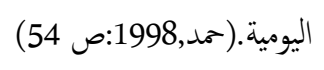

ونظراً لأهمية الدور الهام الذي يلعبه تدريسي الجامعة وكلية العلوم خاصة باعتبارهم أهم العناصر التي تعتمد عليه الجامعة في تحقيق أهدافها, فهم يقومون بتقديم البحوث العلمية التطبيقية من أجل حل مشكلات الجنتع والمساهمة في عمليات التطوير والتنمية الشاملة.(مدان,2008:ص-25), وتطبيق نتائُ البحوث في ميادين الحياة المختلفة, وتخسين معارفهم وخبراتهم العلمية, وزيادة التعمق في مجال تخصصهم.(أبو

$$
\text { دية, 2011, 3 }
$$

يستهدف البحث العلمي التطبيقي استثفر المكتشفات والابتكرات العلمية الحديثة, والتي ينتج عنها البحوث العلمية المنطورة والتي تساهم في زيادة الانتاج وتحسين ادواته باستخدام وسائل تكنولوجية حديثة, ما يؤدي إلى زيادة الارباح والتقدم العلمي الهادف.
محصوراً على الجهد الفردي كالبحوث التي تجري من اجل الحصول على ترقيات او اللقب العلمي التي يقوم بها تدريسي كلية العلوم لتطوير تقنية او حل مشكلة تعترض زيادة الانتاجية وكفاءتها. وهناك تدني وضعف في مستويات البحوث العلمية التطبيقية, وعدم قدرتها على التجديد والتطوير والابنكار او الاختراع, وعدم قدرتها على مسايرة التطورات العلمية والتكنولوجية. وتأسيسا على ما تقدم تحدد مشكلة البحث بالأسئلة الآتية: - - ما المعوقات التي تواجه تدريسي كلية العلوم في أثناء كتابة وتطبيق بحوثم العلمية من وبجة نظر الاساتذة المساعدين والمدرسين؟ - - هل هل هناك فرق في المعوقات التي تواجه تدريسي كلية العلوم في أثناء كتابة وتطبيق بجوثم العلمية من وجحة نظر الاساتذة المساعدين والمدرسين تبعاً

$$
\text { لمتغير اللقب العلمي؟ - nمي }
$$

\section{1 أهمية البحث}

تعتبر الجامعة إحدى المؤسسات المهمة انتاجياً وتربوياً وتعليمياً التي تساهم في زيادة المعرفة وتراكها وتوفير القوى البشرية وتأهيلها من الناحية العلمية

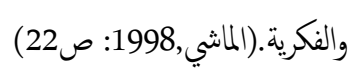

ان تزايد الاهتمام بالبحث العلمي جاء نتيجة تزايد طموح الدول في التطور والتقدم, فبدأت هذه الدول بالبحث عن أساليب علمية وعملية والعمل على إيجاد حلول لمشكلاتها, فكانت النتيجة انتشار مراكز الابحاث العلمية, وأيضاً زيادة الاهتخام بالمؤسسات العلمية والتزبوية بتنمية كفايات البحوث العلمية لدى الباحثين

$$
\text { عوماً.(عبيدات وعدس,1999:ص3) }
$$

فالبحث العلمي التطبيقي يعد وسيلة عمة لتطوير المعرفة، كما انه يساهم بشكل فعال في التجديد والابنكار، فالمنترعات التي يسعد بها الانسان في هذا القرن والتي تقرب له البعيد وتحمل عنه الكثير من الاثقال وتجعل العالم بين يديه هذا

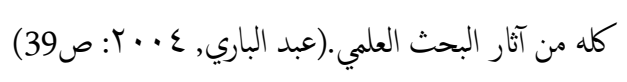

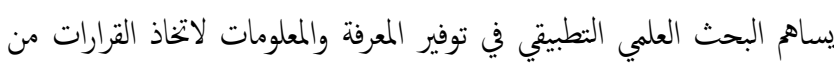
اجل ايجاد حلول للمشكلات وصولاً إلى التقدم, وبفضل البحوث العلمية استطاعت بعض الدول تحقيق التقدم والانتقال من مرحلة التأخر والتخلف إلى لى مرتبة الدول المتقدمة. وعدم إجراء البحوث العلمية التطبيقية في مجتع تعتبر سمة 


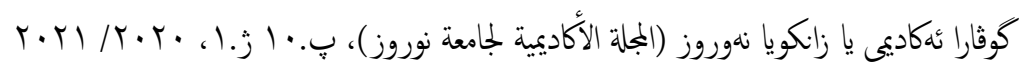

اختصاصه , أو تضعف من هذا النشاط".(العجيلي والففلي ,1988:ص

ب. الجميدل وشاس(2010) بأنها: "جميع العقبات والصعوبات التي تحد او تحول دون انجاز اعضاء هيئة التدريس بالجامعة لأبحاث علمية أو انخراطهم في مجال البحث العلمي، وتشكل عقبة في نشاطهم العلمي أو تشكل عقبة في نثاطهم العلمي، سواء اكانت عقبات مادية ام معنوية ام ادارية"(المجيدل

$$
\text { وشماس,2010:ص 27) }
$$

الريماوي والكردي(2015) بأنها: "جميع الصعوبات التي تعوق عضو هيئة التدريس من إجراء البحوث العلمية بالشكل المطلوب، أو تقديها في الوقت المناسب وتختلف هذه الصعوبات باختلاف بيئة العمل".(الريماوي

$$
\text { والكردي,2015:ص 25 (25) }
$$

د. رابجي (2016) بأهها: "بموعة المعيقات او العقبات التي تقف عثرة امام الباحث سواء منها المادية او المعنوية تحول دون إنجاز أعضاء الهيئة التدريسية لأبحاث علمية أو انخراطهم في مجال البحث العلمي أو تشكل

$$
\text { عقبة في نشاطهم العلمي.(رابجي,2016: ص20) }
$$

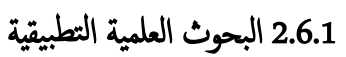

أ. نعهان والتمري (1998) بأنه: "هو البحث الذي يعتمد على الواقع وعلى الاستقراء العلمي، ويقوم الباحث به عادة بعدما يوحي له بعض الملاحظات والتجارب بغرض معين يصوغه صياغة دقيقة و محددة وقابلة للقياس الكي".(ن نعان والتمري,1998:ص 28)

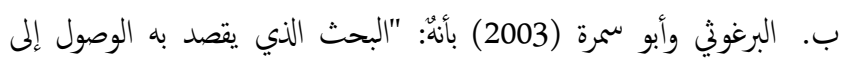

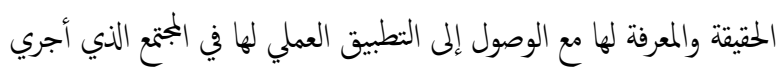
فيه البحث, وهذا النوع من البحث يركز على المشكلات وحلها كما يركز على الابنكار".(البرغوثي وأبوسمرة,2003:ص 1135- 1136) ج. ناجي (2011) بأنهُ: "البحث المستخدم في العلوم التطبيقية التجريبية ولملاحظة والتجربة دورها الواضح في هذا النوع من البحوث، وغالبا ما يسعى صاحبه لإيتكار جديد أو إيجاد حل لمشكلة، أو التوصل لطريقة مفيدة وعملية، أو لتسخير المكتشفات العلمية الحديثة لمضاعفة الإنتاج وتقليل النفقات والتكليف، مما يؤدي بالتالي إلى مضاعفة الأرباح والتقدم

$$
\text { العلمي المنشود".(ناجي,2011:ص 53 ) }
$$

يبحث البحث العلمي التطبيقي في مسائل عملية والمساعدة في إيهاد حل لمشكلات عملية معينة في الحياة, فعملها دراسة مزايا وقيمة عمل ما في موقع محدد أو مواقع محددة, كما ان الهدف لإجرائه إيجاد حل لمشكلة واتخاذ إجراءات معينة تجاهها, والاستفادة منها في تطوير العمل وتحسينه, وهذا النوع من البحث لا يستطيع تحقيق أهداف وفوائد مرجوة إلا إذا استند إلى البحث العلمي في مجالات البحوث الاخرى والنزابط بنهها.(جودت,2014: الانتزيت)

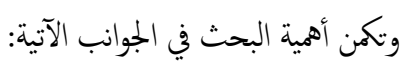

يعد البحث محاولة للتعرف على المعوقات التي تواجه تدريسي كلية العلوم في ج. أثناء كتابة وتطبيق بحوثم العلمية من وبهة نظر الاساتذة المساعدين

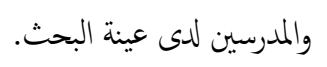

$$
\text { يعتبر انطلاقًا لبحوث مستقبلية في هذا التجاه. }
$$

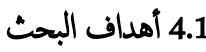

مهدف البحث الحالي إلى التعرف على المعوقات التي تواجه تدريسي كلية العلوم في أثناء كتابة وتطبيق بجوثم العلمية من وجهة نظر الأساتذة المساعدين والمدرسين

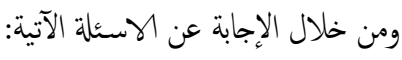
- س1/ ما مدى المعوقات التي تواجه تدريسي كلية العلوم في أثناء كتابة وتطبيق بحوثم العلمية من وجهة نظر الاساتذة المساعدين والمدرسين ؟ -س2/ هل هناك فرق ذو دلالة احصائية وعند مستوى (0.05) في المعوقات التي تواجه تدريسي كلية العلوم في أثناء كتابة وتطبيق بحوثم العلمية من وبجة نظر الاساتذة المساعدين والمدرسين تبعاً لمتغير اللقب العلمي؟

5.1

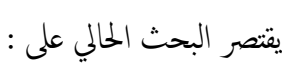
- - تدريسي كلية العلوم جامعة دهوك (مدرس- استاذ مساعد) للدراسات الصباحية للسنة الدراسية (2019- 2020).

( 6.1 تحديد المصطلحات

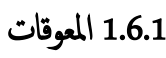
أ. العجيلي والفلفلي (1988) بأنها: "الصعوبات و العقبات والمشكلات التي تواجه التدريسي , والتي تقف حائلاً دون مزاولة نشاطه ضمن مجال 


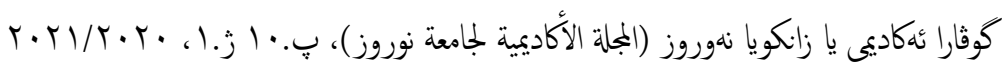

المحلية, وما ينتج عنه من زيادة في تشوق طلبته للمادة الذي يدرسها, وزيادة

$$
\text { فرصة حصولم على العمل بعد التخرج. }
$$

- - لا يككن حصول الاستاذ الجامعي على التزقية إلا من خلال القيام بأبحاث

$$
\text { دراسية منشورة ومككة.(الفرا,2004:ص 3) }
$$

\section{2 الوسائل والتثنيات الحديثة في تقدم البحث العلمي:}

من أهم الوسائل والتقنيات الحديثة في تقدم البحث العلمي وهي:

$$
\text { أ. أ. الكومبيوتر. }
$$

ب. المكتبة والمصادر والمراجع والندوات العلمية وكذلك المؤتمرات التي تعقد في

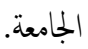

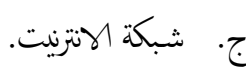

د. توفير وسائل العمل مثل المعدات والأجزة والمختبرات المتطورة والحديثة

وورشات العمل الحديثة. (الربيعي: 2007:ص 25)

7.2 الصعوبات التي تواجه البحث العلمي التطبيقي

- مقاة برامج الندريب والتأهيل التي تنظمها الجامعات.

- - - قلة العمل في المراكز البحثية ووحداتها في الجامعة.

- - معف قاعدة المعلومات في المراكز والمختبرات والمؤسسات الإنتاجية العلمية.

- - مقلة المؤهلين في أساسيات البحث العلمي ومتطلباته التطبيقة.

- - عدم وجود إمكانيات تساعد الباحثين مثل المختبرات الحديثة, والأجهزة المتقدمة و ورش العمل التي تنشط الباحثين وتسند طموحاتهم, وأيضاً عدم

\section{وجود بيانات حديثة على النشاطات البحثية.}

- - لا يوجد تنسيق بين الجامعة وجامعات الدول المتقدمة في القيام بمشاريع

مشتركة إلا بشكل قليل جداً.

- عدم وجود بجة تقوم بنمويل البحث العلمي التطبيقي

$$
\text { وتطويرها.(عباس,2005:ص 58) }
$$

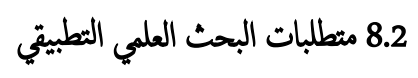

- - بيئة العمل: على الجامعة ان تخلق البيئة المناسبة للبحث العلمي, وذلك من خلال إيجاد المكان المناسب, وتكليف عضو هيئة التدريس أعباء تدريس مناسبة, واعتبار عمله البحثي جزء من عطائه الجامعي.
د. الثريف(2014) بأنهُ: "ذلك النوع من البحوث التي تهدف لحل مشكلة

علمية أو لاكتثاف شيء جديد يضاف إلى المعرفة العلمية على الصعيد

النظري أو التطبيقي". (الثريف,2014:ص 407)

2. الإطار النظري: تصنيف البحوث العلمية

1.2 البحوث النظرية أو الأساسية

هو البحث الذي يقوم به الباحث لإشباع حاجته من المعرفة وتوسيعها، وتوضيح غوض في ظاهرة ما، دون النظر إلى مدى تطبيق نتائجه في الميدان، ويكون الدافع لهذا النوع من البحث السعي وراء الحتيقة وتطوير المفاهيم النظرية ومحاولة الوصول إلى معارف جديد. (النجار وآخرون,2010:ص 50)

2.2

وبهدف هذا النوع من البحوث إلى معالجة مشكلات قائة لدى المؤسسات الاجتاعية والاقتصادية، حيث يقوم الباحثون المعنيون بتحديد واضح للمشكلات التي تعاني منها تلك المؤسسات مع التأكد من صحتها ودقة أسباها ميدانياً وذلك من خلال استخدام أو إتباع منهجية علمية ذات خطوات بكثية متدرجة وصولاً لمجموعة من الأسباب الفعلية نسبياً التي أدت إلى حدوث هذه المشكلات أو الظواهر مع اقتران بموعة من التوصيات العلمية التي يككن أن تسهم في التخفيف من حدة هذه المشكلات أو معالجتها نهائياً. (عبيدات وآخرون,1999:ص 6) كري

3.2 بحوث التطوير الهدف منها تطوير التقنيات العلمية الموجودة من اجل زيادة كفاءة الانتاج وتحسين كمية النوع من خلال ترجمة نتابُج البحوث النظرية والتطبيقية وتكييف نتأُجها إلى منتجات بحيث يكن الاستفادة منها في تسويقها بشكل تجاري مفيد

4.2

وهي تهدف إلى تحسين وسائل العمل من أجل مساعدة البحوث العلمية والنظرية والتطبيقية لتسهيل عملها وتشمل المعدات و الأدوات والاجهزة والحزائط.(انطوان,1997:ص 6)

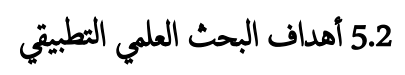

- يعتبر جزءاً هماً في حياة الأستاذ الجامعي العلمية, حيث يعطي الاستاذ الفرصة على الربط بين النظرية بالواقع, وهذا يزيد من ربط الاستاذ بالبيئة 
نظر الادارة الككاديمة واعضاء هيئة الندريس, تكونت عينة البحث من اعضاء الادارة الكاديمية واعضاء هيئة التدريس والبالغ عدده (518) فرداً وتبعاً لمنغير (الجنس, نوع المؤسسة الكاديمية, اللقب العلمي, الكلية, الخبرة, الجامعة التي

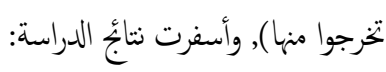

- - ان جميع مجالات المعيقات حصلت على درجة متوسطة ماعدا المعوقات

$$
\text { المالية وظروف العمل كان الوسط الحسابي اعلى. }
$$

- وجود فروق ذات دلالة احصائية عند مستوى (0.05) في درجة معيقات

$$
\text { تبعاً لمتغير اللقب العلمي لصاح استاذ. }
$$

- - عدم وجود فرق ذو دلالة احصائية عند مستوى (0.05) بين المتوسطات الحسابية لمجالات معيقات البحث العلمي تبعاً لمتغر العمل الحالي الإداري.

2006) (المعوقات التي تعرقل او تقلل من مسيرة البحث العلمي في جامعة كربلاء) هدفت الدراسة غلى التعرف على المعوقات التي تعرقل او تقلل من مسيرة البحث العلمي في جامعة كربلاء, تكونت عينة الدراسة من (52) من اعضاء هيئة التدريس من يحملون اللقب العلمي (استاذ- استاذ مساعد- مدرس), ولتحقيق هدف البحث اعد الباحث الاستبيان اداة لبحثه حيث تكونت من (22) فقرة,

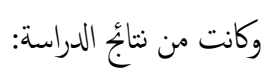

- - ان درجة وجود المعوقات لدى اعضاء هيئة التدريس كانت بدرجة عالية

$$
\text { بشكل عام. }
$$

- ـ وكانت من المعوقات التي احتلت المراتب المرتب الاولى في استجابات عينة الدراسة وهي بالترتيب التنازلي منها (قلة المصادر والمراجع العلمية, قلة التخصيصات المالية للبحوث, الانعكات السلبية للآثار النفسية التي تسبيها الاوضاع الهنية الغير المستقرة في المنطقة, الاعباء التدريسية للتدريسين, والتزكيز على التدريس اكثر من البحوث, وهجرة التدريسين ذات الكفاءة العالية إلى خارج القطر , وقلة ايفاد التدريسين الى الدول المتقدمة).

3.3 بطاح (2007) (المعيقات التي تقف في وجه البحث العلمي في جامعة مؤتة من وبجة نظر اعضاء هيئة التدريس) هدفت الدراسة الى التعرف على المعيقات التي تقف في وجه البحث العلمي في جامعة مؤتة من وبجة نظر اعضاء هيئة الندريس, وتكونت عينة
- - دئم التمويل المالي: أن النمو الاقتصادي مرتبط تماماً بمدى الانفاق والاستثمار في مجال التعليم العالي والبحث العلمي, وانه مرتبط بدعز التعليم الجامعي. - - توفير الكفاءات البشرية اللازمة: الكفاءات البشرية اللازمة تتكون من العلماء الباحثين النواة, وما يلزم من باحثين مساعدين, وفنيين, وعال همرة

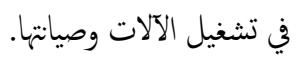

- - التدريب والتأهيل: ان تشجيع اعضاء هيئة التدريس على الأعمال الاستشارية والمشاركة كستشارين وأعضاء في اللجان الحكومية وإدارة الشركات وتقييم المشروعات وتنفيذها يولد الخبرة العلمية وتنمية القدرة الاستشارية الفنية لدى اعضاء هيئة التدريس. (أبو دية,2011:ص 10-

- - العمل على إنشاء قناة الاتصال مع القطاع العام والخاص, لمعرفة احتياجتهها ووضع الخطط القصيرة والمتوسطة والبعيدة المدى قصيرة ومتوسطة المدى. - كبب ثقة القطاع الخاص بشكل خاص لأنه يتطلع الى الربح

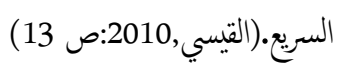
- - تخصيص ميزانية للبحوث العلمية التطبيقة وخاصة المتعلقة بالجانب الأكادييي والتقني وتسهيل التسويات المالية وإجراءاتها وتوفير المرونة الكافية لتمويل البحث وتوفير الأجهزة والمعدات اللازمة خاصة في مراكز البحث العلمي لمساعدة الباحثين على القيام ببحوثه. - - توفير وتطوير ورش عمل والمعدات والمختبرات والأجهزة العلمية وغيرها من الإمكانيات والطاقات العلمية والتكنولوجية في مؤسسات التعليم العالي بما

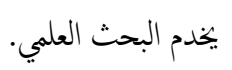

- تخصيص جهة أو إدارة تعمل على ربط مراكز البحوث بشبكات قواعد المعلومات الدولية والعمل على تشجيع الأبحاث العلمية

$$
\text { المتميزة.(العمايزة,2005:ص 19) }
$$

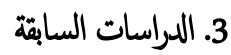

(2006) (واقع البحث العلمي ومعيقانه بؤسسات التعليم العالي في سلطنة عان من وبجة نظر الادارة الكاديمية واعضاء هيئة الندريس) هدفت الدراسة الى التعرف على واقع البحث العلمي ومعيقانه بمؤسسات التعليم العالي في سلطنة عان من وبجة 


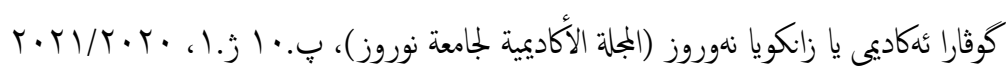

- - وجود فروق ذات دلالة احصائية عند مستوى (0.05) في درجة تقدير اعضاء هيئة الندريس لمقترحات تطوير البحث العلمي تبعاً لمتغير الجنس

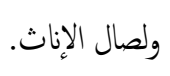

- عدم وجود فروق ذات دلالة احصائية عند مستوى (0.05) في درجة تقدير اعضاء هيئة الندريس لمقترحات تطوير البحث العلمي تبعاً لمنغير الخبرة.

\section{3 جوانب الإفادة من الدراسات السابقة}

- - تحديد مشكلة البحث: أي أنها تكشف عن استقصاءات حول المشكلة

$$
\text { وتشابها مع المشكلة التي نود دراستها. }
$$

- - الوسائل الإحصائية التي تلائم الدراسة: أي كيفية معالجة بيانات البحث

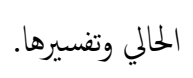

- - اعداد أداة البحث: كلاطلاع على الأدوات والاختبارات التي قام بها من سبق لحل المشكلات التي وابتهم في بحوثم وبنوا على أساسها دراساته.

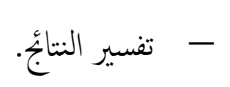

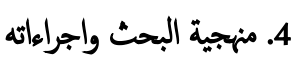

اتبعت الباحثة في هذه الدراسة المنهج الوصفي في تحديد بمتع البحث وطريقة اختيار عينة البحث و وصف أداة الدراسة وإجراءات الصدق والثبات وتطبيق الاداة والوسائل الاحصائية المستخدمة لتحليل البيانات.

\section{4}

ككون مجتمع البحث من تدريسي كلية العلوم / جامعة دهوك (مدرس, استاذ

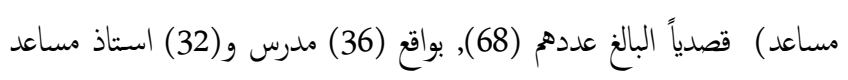
للادراسات الصباحية للسنة الدراسية (2019- 2020).

\section{4 عينة البحث}

بعد تحديد مجتع البحث من تدريسي كلية العلوم / جامعة دهوك قصدياً , تم

\begin{tabular}{|c|c|c|}
\hline النسبة المثوية & العدد & اللقب العلمي \\
\hline \multirow{3}{*}{58.82} & 20 & المدرس \\
\hline & 20 & استاذ مساعد \\
\hline & 40 & المجموع \\
\hline
\end{tabular}
اختيار (20) مدرس و(20) استاذ مساعد من كلية العلوم. جدول رجّ (1) عدد أفراد العينة
البحث من (154) اعضاء هيئة التدريس, ولتحقيق هدف البحث أعد الباحث

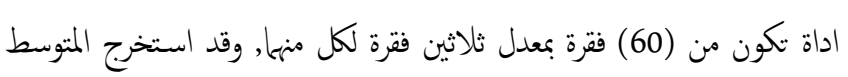
الحسابي والانحراف المعياري والرتب واختبار (t.test), وكانت من نتائج الدراسة: - - ان هناك عدداً من المعوقات التي تحول دون تقدم البحث العلمي في جامعة

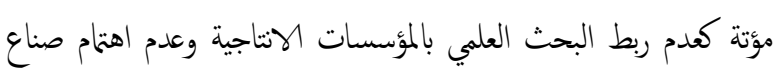

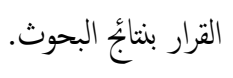

- - وبينت النتائُ بأن هناك فروقاً بين الكليات العلمية والانسانية فيا يتعلق

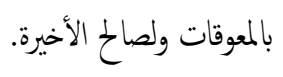

(2008) 4.3 الفتلي (المعوقات التي تواجه الباحث العلمي الجامعي في الجامعات العراقية) هدفت الدراسة الى معرفة المموقات التي تواجه الباحث العلمي الجامعي, , وتكونت عينة البحث من (200) اعضاء هيئة التدريس جامعة القادسية, ولتحقيق هدف البحث أعد الباحث أداة الاستبيان تكونت من (26) فقرة, وبعد تحليل البيانات ومعالجتها احصائياً توصلت النتائُ الى ان : لبان - - ان ان العم الملالي من اكثر المعوقات التي تواجه الباحث العلمي. - عدم وجود ذو دلالة احصائية يعزي لمتغير الجنس واللقب العلمي.

(الع العيرة والسرابي (2008):

\section{(معوقات البحث العلمي لدى اعضاء هيئة الثدريس بجامعة الإسراء الخاصة)} هدفت الدراسة إلى التعرف على معوقات البحث العلمي لدى اعضاء هيئة التدريس بجامعة الإسراء الخاصة, وتكونت عينة البحث من (80) عضو هيئة التدريس جامعة الإسراء الخاصة, ولتحقيق هدف البحث تم إعداد أداة الاستبيان تكونت من (36) فقرة موزعة على مجالين, وبعد تحليل البيانات ومعالجتها احصائياً

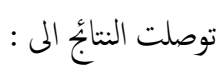
- - مجود معوقات تحول دون قيام اعضاء هيئة التدريس بالبحث. - - مجود فروق ذات دلالة احصائية عند مستوى (0.05) في درجة تقدير اعضاء هيئة التدريس لمعوقات البحث العلمي تبعاً لمنغير الجنس ولصال

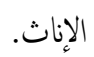
- - عدم وجود فروق ذات دلالة احصائية عند مستوى (0.05) في درجة تقدير اعضاء هيئة التدريس لمعوقات البحث العلمي تبعاً لمتغير الخبرة. 


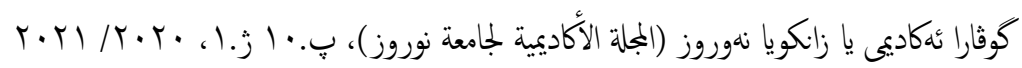

مدرس واستاذ مساعد من كلية العلوم جامعة دهوك, وعند توزيع المقياس عليهم طلبت الباحثة منه الإجابة على نفس ورقة المقياس وذلك بالتأشير على البديل الذي يناسب وبجة نظرهم لتحقيق هدف البحث مع حثم بالإجابة على كل فقرات الاستبيان دون ترك أي فقرة وذلك يوم الأربعاء الموافق (2019/12/2).

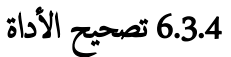

اعتمدت الباحثة في تصحيح الأداة على اعطاء الأوزان (1,2,3) للبدائل بدرجة (كبيرة ومتوسطة وقليلاً) على التوالي في ضوء ذلك تم جعع درجات الإجابة عن

كل الفقرات المكون من (25) فقرة وكانت الدرجة تتزاوح بين ( 25- 75).

4.4 الوسائل الوحصائية

استخدمت الباحثة الوسائل الاحصائية الآتية: هعلم ارتباط بيرسون: لإستخراج ثبات مقياس التطبيق.(البياتي,2008:

$(140$

الوسط الحسايي: لإيجاد التمييزية بين الفقرات.(المنيزل وعايش,2006: 239)

اختبار (t.test) لعينتين مستقلتين وذلك باستخدام برنامج (spss).

\subsection{4 عرض النتائج وتفسيرها}

بعد جمع البيانات من استجابات افراد عينة الدراسة وتحليلها احصائياً تبعاً لأسئلة البحث, سوف تقوم الباحثة بعرض ننائج البحث وعلى النحو الآتي:

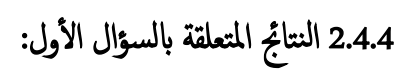

"ما مدى المعوقات التي تواجه تدريسي كلية العلوم في أثناء كتابة وتطبيق بحوثهم

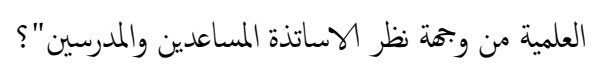

وللإجابة عن السؤال الأول استخرجت الباحثة الحدة والوزن النسبي لكل فقرة من فقرات الاستبيان لعينة البحث (مدرس- أستاذ مساعد), وكما هو

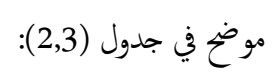

يتضح من جدول (2) ان بضع فقرات المقياس سجلت نسبها أكثر من المتوسط الفرضي البالغ (50) درجة للأداة كلل, وهذا يعني ان المعوقات التي تواجه تدريسي كلية العلوم أثناء كتابة وتطبيق بحوثهم العلمية من وبجة نظرهم تبعاً لمتغير الرتبة العلمية ككل عدا الفقرات (12,13,14,16,17,22,24) على التوالي

\begin{tabular}{|c|c|c|c|}
\hline التزيب & الوزن & درجة & ت الفقرة \\
\hline الجديد & النسبي & الحدة & \\
\hline
\end{tabular}
جدول روّ 2: درجات الحدة والوزن النسبي لفقرات الاستبيان لعينة (مدرس)
3.4

1.3.4 أداة البحث

اعتمدت الباحثة في التعرف على المعوقات التي تواجه تدريسي كلية العلوم في أثناء كتابة وتطبيق بحوثه العلمية من وبجة نظر الاساتذة المساعدين والمدرسين على استبانة أعدتها الباحثة من خلال اطلاع الباحثة على الدراسات السابقة والاتصال مع بعض الاساتذة المساعدين ومدرسي كلية العلوم والسؤال عنهم عن المعوقات التي تواجتهم أثناء كتابة وتطبيق بحوثم العلمية من وجهة نظرهم والتي نكونت من (25) فقرة موزعة على ثلاث بدائل وهي بدرجة (كبيرة, متوسطة, قليلاً).

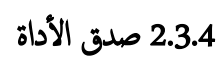

لغرض استخراج الصدق الظاهري تم عرض الأداة على بمموعة من المحكين المختصين في مجال العلوم التزبوية والنفسية من ذوي الخبرة والاختصاص وذلك لإبداء آرائه ومقترحاتهم على فقرات المقياس, وبناءاً عليه تم قبول جميع الفقرات, كما تم إجراء التعديلات اللغوية على عدد من الفقرات على وفق اقتراحات السادة المحكين لتناسب هدف البحث. وقد اعتمدت الباحثة نسبة (80\%) فأكثر من

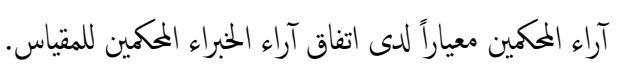

3.3.4 بات الأداة وقد استخدمت الباحثة طريقة إعادة الاختبار لاستخراج الثبات لأداة البحث، إذ طبقت المقياس على عينة استطلاعية مكونة من (20) مدرس واستاذ مساعد

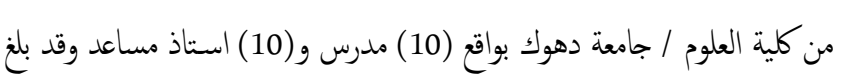
(83\%) وهو معامل ثبات مقبول وبذلك تم التحقق من ثبات المقياس يوم الاثنين الموافق ( 2019/11/4) وجرت الإعادة يوم الثلاثاء الموافق (2019/11/19) وبعد ذلك تم حساب معامل ارتباط بيرسون بين درجات الندريسين في التطبيقين الاول والثاني, ولم تدخل عينة الاستطلاع في التطبيق الأخير للاستبيان.

\subsection{4 وصف المقياس}

أعطت الباحثة الأوزان (1,2,3) للبدائل بدرجة (كبيرة, متوسطة, قليلاً) على التوالي في ضوء ذلك تم جمع درجات الإجابة عن كل الفقرات المكون من (25) فقرة وكانت اعلى درجة (75) وأدنى درجة (25) والوسط الفرضي (50).

5.3.4 تطبيق الأداة

طبقت الباحثة المقياس بالصورة النهائية على أفراد عينة البحث المكونة من(40) 


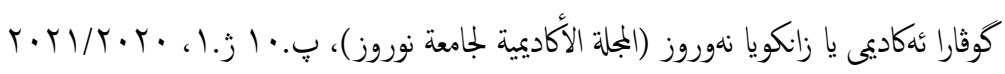

يعني بأن المعوقات التي تواجه تدريسي كلية العلوم قد كانت تنمثل في عدم تخصيص الجامعة موازنة لإجراء البحث العلمي التطبيقي و اهتمام الجامعة الأولية بالتدريس بدل البحوث العلمية التطبيقية وأيضاً افتقار مكتبة الكلية للدوريات والمجلات العلمية على شكل اونلاين وكذلك عدم وجود الصناعة بجيث لا تحتاج إلى نتائج البحوث العلمية و نقص وجود معامل ومختبرات حديثة لازمة للبحث و يجتاج الانتاج العلمي إلى بجد كير جداً و اعتاد القطاعات على استيراد التقنية بدلاً من إجراء البحوث وعدم قناعة ادارة الكلية بأهمية البحث العلمي التطبيقي لتطوير الكلية و قلة الهككات المادية للباحثين لإجراء البحث و عدم توفر مساعدين متخصصين لتقديم المساعدة الفنية والاحصائية للباحثين و انخفاض مستوى الوعي عند القطاع الخاص بأهمية البحث العلمي التطبيقي و ضعف الحوافز المعنوية المقدمة من قبل الجامعة للباحثين و كثرة الإجراءات الروتينية المتعلقة بالتسويات المالية ولا يثق اصحاب القطاع الخاص بإمكانية الجامعة في ايجاد حلول لمشكلاتهم التي تواجتهم وفضلاً عن قلة المكافة المالية التي ترتبط بالإنتاج العلمي و المواد الخمتبرية غالية الثثن و المعلومات التي يزود بها الباحثين يتأثز بالعلاقات الشخصية والمزاج و قلة اطلاع الباحثين على النجارب المتقدمة للاستفادة منها و ضعف إتقان اعضاء هيئة التدريس للغات الأجنبية و العبء التدريسي الكبير الذي يتحمله الباحثين و كثرة ارتباطات الباحثين والاتزامات العائلية و الالتزامات الإدارية للباحث و ضعف اتقان الباحثين لمهارات الحاسب الآلي في استخدام بحثه و قلة خبرة الباحثين في مجال بجثه العلمي و تأخر النثر في الدوريات العلمية. هذا حسب وبجة نظر تدريسي كلية العلوم (مدرس). تعزي الباحثة هذه النتيجة إلى ان المعوقات التي يوابهها تدريسي كلية العلوم من حيث ظروف ومناخ البحث العلمي التطبيقي شبه موحدة على الجميع, إذ ان مجملها تشمل قلة الدع المادي والمعنوي وعدم وجود المناخ المشجع للبحث, وهذا يعني وجود مشكلات كيرة تعيق قيامهم بالبحوث العلمية. يتضح من جدول (3) ان بضع فقرات المقياس سبلت نستها أكثر من المتوسط الفرضي البالغ (50) درجة للأداة ككل, وهذا يعني ان المعوقات التي تواجه تدريسي كلية العلوم أثناء كتابة وتطبيق بحوثم العلمية من وبجة نظره تبعاً لمثغير اللقب العلمي ككل عدا الفقرات (22,24, 12,13,14,16) على التوالي وسبحت قيم متقاربة إلى حد ما من المتوسط الحسابي كلها مؤشراً على ضعف المعوقات

جدول رجّ 3: درجات المدة والوزن النسبي لفقرات الاستبيان لعينة (أستاذ مساعد)

\begin{tabular}{|c|c|c|c|}
\hline 8 & 90 & عدم قناعة ادارة الكلية بأهمية البحث العلمي 2.7 & 1 \\
\hline 1 & 95 & عدم تخصيص الجامعة موازنة لإجراء البحث 2.85 & 2 \\
\hline 10 & 88.33 & 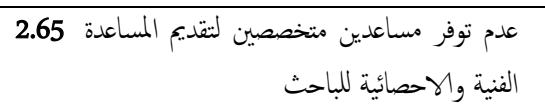 & 3 \\
\hline 2 & 93.33 & 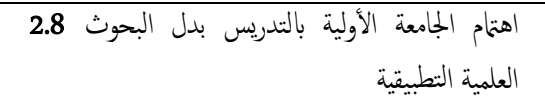 & 4 \\
\hline 5 & 91.66 & نقص وجود معامل ومختبرات حديثة لازمة للبحث 2.75 & 5 \\
\hline 16 & 65 & المواد الخختبرية غالية الثمن $1.95 \quad$ & 6 \\
\hline 9 & 90 & قالة الامكانات المادية للباحث لإجراء البحث $\quad 2.7 \quad$ & 7 \\
\hline 15 & 66.66 & 2 ق 2 & 8 \\
\hline 17 & 58.33 & 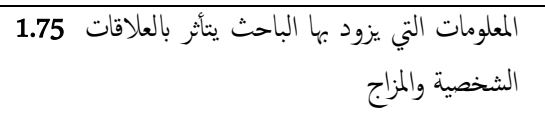 & 9 \\
\hline 18 & 50 & للاستفادة منها اطلاع الباحث على التجارب المتقدمة 1.5 & 10 \\
\hline 3 & 93.33 & على شكل اونلارين مكنبة الكلية للدوريات والمجلات العلمية 2.8 & 11 \\
\hline 19 & 43.33 & ضألجف إتقان اعضاء هيئة التدريس للغات 1.3 & 12 \\
\hline 20 & 40 & العبء التدريسي الكيبر الذي يتحمله الباحث & 13 \\
\hline 23 & 36.66 & ضعف استخدام الباحث لمهارات الحاسب الآلي في 1.1 & 14 \\
\hline 6 & 91.66 & يحتاج الانتاج العلمي إلى بجد كير جداً & 15 \\
\hline 24 & 35 & قلة خبرة الباحث في بجال بكثه العلمي & 16 \\
\hline 21 & 40 & كثرة ارتباطات الباحث والالتزامات العائلية & 17 \\
\hline 12 & 85 & 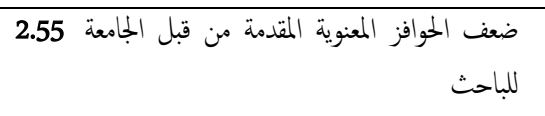 & 18 \\
\hline 4 & 93.33 & البحوث العلمية وجود الصناعة بحيث لا تحتاج إلى نتائج 2.8 & 19 \\
\hline 7 & 91.66 & إجراء البحوث القطاعات على استيراد التقنية بدلاً من 2.75 & 20 \\
\hline 11 & 86.66 & بأهمة البحث العلمي التطبيقي اضوى عند القطاع الخاص 2.6 & 21 \\
\hline 22 & 40 & الالتزامات الإدارية للباحث & 22 \\
\hline 13 & 85 & كالمثة الإجراءات الروتينية المتعلقة بالتسويات 2.55 & 23 \\
\hline 25 & 35 & تأخر النشر في الدوريات العلمية & 24 \\
\hline 14 & 81.66 & 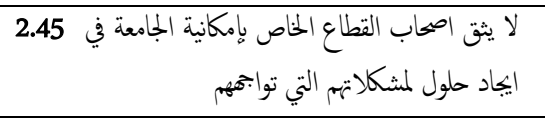 & 25 \\
\hline & 1766.6 & الكلي & \\
\hline
\end{tabular}

وسبلت قيم متقاربة إلى حد ما من المتوسط الحسابي كلها مؤشراً على ضعف المعوقات التي تواجه تدريسي كلية العلوم لكن ليس بالمستوى المطلوب, وهذا 


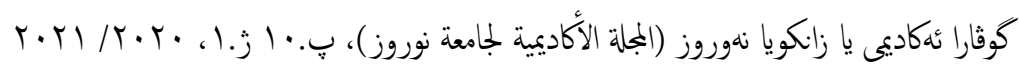

نتابُج البحوث العلمية وأيضاً نقص وجود معامل ومختبرات حديثة لازمة للبحث و اهتمام الجامعة الأولية بالتدريس بدل البحوث العلمية التطبيقية و يحتاج الانتاج العلمي إلى جهد كير جداً و كثرة الإجراءات الروتينية المتعلقة بالتسويات المالية و عدم توفر مساعدين متخصصين لتقديم المساعدة الفنية والاحصائية للباحثين و افتقار مكنبة الكلية للدوريات والمجلات العلمية على شكل اونلاين وقلة الهمكانات المادية للباحثين لإجراء البحث و اعتاد القطاعات على استيراد التقنية بدلاً من إجراء البحوث وانخفاض مستوى الوعي عند القطاع الخاص بأهمية البحث العلمي التطبيقي و قلة المكآفة المالية التي ترتبط بالإنتاج العلمي و عدم قناعة ادارة الكلية بأهمية البحث العلمي التطبيقي لتطوير الكلية و قلة اطلاع الباحثين على التجارب المتقدمة للاستفادة منها و المواد الخختبرية غالية الثمن و لا يثق اصحاب القطاع الخاص بامكانية الجامعة في ايجاد حلول لمشكلاتهم التي توابتهم و المعلومات التي يزود بها الباحثين يتأثر بالعلاقات الشخصية والمزاج و قلة الحافز المعنوي المقدم من قبل الجامعة و كثرة ارتباطات الباحثين والالتزامات العائلية و ضعف إتقان اعضاء هيئة التدريس للغات الأجنبية و قلة خبرة الباحثين في مجال بجثه العلمي و الالتزامات الإدارية للباحثين و ضعف اتقان الباحثين لمهارات الحاسب الآلي في استخدام بكثه و تأخر النشر في الدوريات العلمية و العبء التدريسي الكبير الذي يتحمله الباحثين. هذا حسب وبجة نظر تدريسي

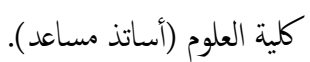

تعزي الباحثة هذه النتيجة إلى ان المعوقات التي يوانهها تدريسي كلية العلوم من حيث ظروف ومناخ البحث العلمي التطبيقي شبه موحدة على الجميع, إذ ان مجملها تشمل قلة الدع المادي والمعنوي وعدم وجود المناخ المشجع للبحث, وهذا يعني وجود مشكلات كيرة تعيق قيامم بالبحوث العلمية.

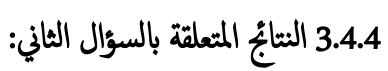
"هل هناك فرق ذو دلالة احصائية ومستوى دلالة (0.05) في المعوقات التي تواجه تدريسي كلية العلوم في أثناء كتابة وتطبيق بحوثه العلمية من وبجة نظر الاساتذة المساعدين والمدرسين تبعاً لمتغير اللقب العلمي"؟ ولتحقيق هذا الهدف تم استخراج الوسط الحسابي والانراف المعياري والتمة التائية المحسوبة والجدولية كما في جدول (4):

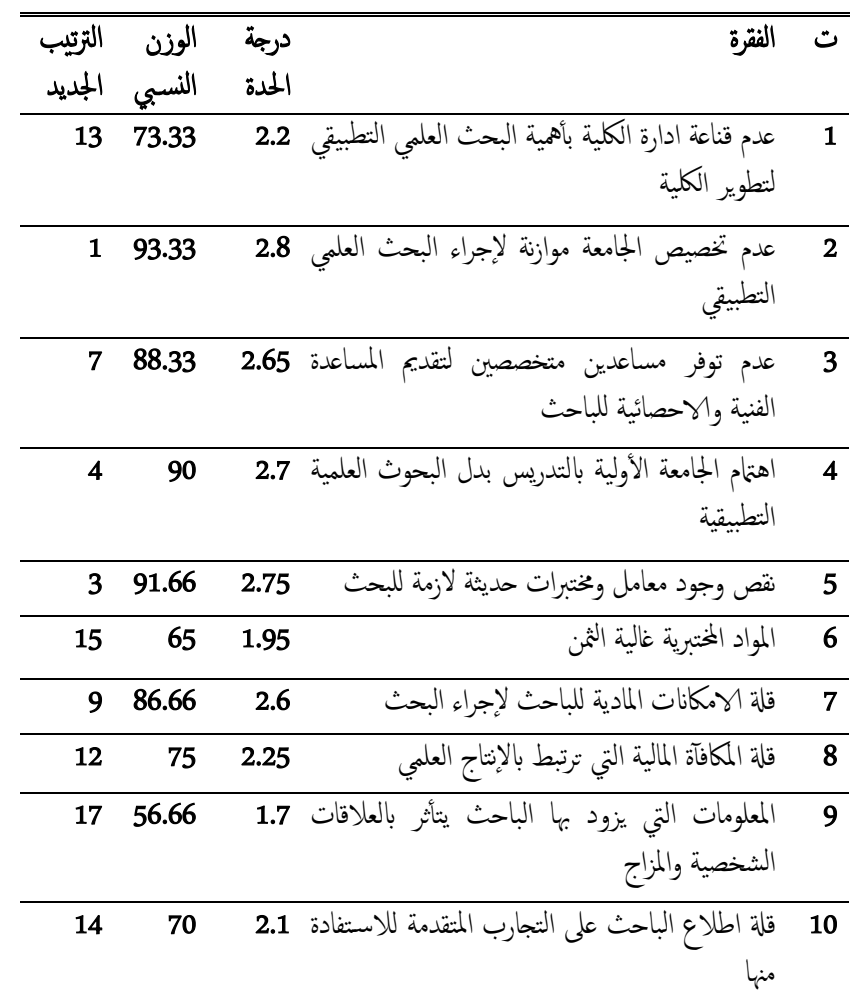

$\begin{array}{lllll}8 & 88.33 & 2.65 & & \end{array}$ شكل اونلاين

\begin{tabular}{|c|c|c|c|}
\hline 20 & 45 & 1.35 & ضعف إتقان اعضاء هيئة التدريس للغات الأجنبية \\
\hline 25 & 35 & 1.5 & العبء الندريسي الكبير الذي يتحماه الباحث \\
\hline
\end{tabular}
استخدام بكثة أنسف

\begin{tabular}{|c|c|c|c|c|}
\hline 5 & 90 & 2.7 & يكتاج الانتاج العلمي إلى بحد كبير جداً & 15 \\
\hline 21 & 45 & 1.35 & قلة خبرة الباحث في مجال بحثه العلمي & 16 \\
\hline 19 & 50 & 1.6 & كثرة ارتباطات الباحث والاكتزامات العائلية & 17 \\
\hline 18 & 53.33 & 1.05 & قلة الحافز المعنوي المقدم من قبل الجامعة & 18 \\
\hline 2 & 93.33 & 2.8 & علدم وجود الصناعة بحيث لا تختاج إلى نتاجُ البحوث & 19 \\
\hline 10 & 86.66 & & البحتاد القطاعات على استيراد التقنية بدلأ من إجراء & 20 \\
\hline 11 & 78.33 & 2.35 & البحث العلمي التطبيقي الوعي عند القطاع الخاص بأهمية & 21 \\
\hline 22 & 41.66 & 1.25 & الالتزامات الإدارية للباحث & 22 \\
\hline 6 & 90 & 2.7 & كثرة الإجراءات الروتينية المتعلقة بالتسويات المالية & 23 \\
\hline 24 & 36.66 & 1.1 & تأخر النشر في الدوريات العلمية & 24 \\
\hline 16 & 60 & & 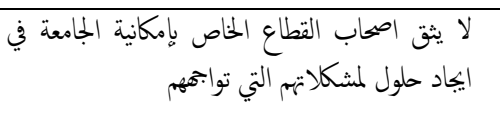 & 25 \\
\hline & 1720.61 & 51.65 & & \\
\hline
\end{tabular}

تواجه تدريسي كلية العلوم لكن ليس بالمستوى المطلوب, وهذا يعني بأن المعوقات التي تواجه تدريسي كلية العلوم قد كانت تتمثل في عدم تخصيص الجامعة موازنة لإجراء البحث العلمي التطبيقي وكذلك عدم وجود الصناعة بحيث لا تحتاج إلى 


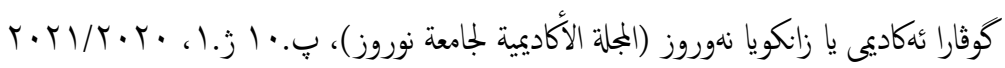

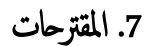

إجراء دراسة مماثلة لمعرفة المعوقات التي تواجه تدريسي الكليات الانسانية.

إجراء دراسة مقارنة بين جامعات القطر لمعرفة مدى المعوقات التي توابتهم.

إجراء دراسة مقارنة بين الكليات الانسانية والكليات العلمية لمعرفة مدى

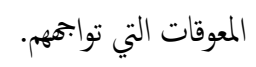

إجراء دراسة تهدف إلى وضع حلول ومقترحات علاج للمعوقات التي تواجه

$$
\text { أعضاء هيئة الندريس. }
$$

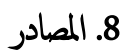

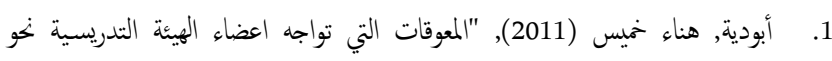

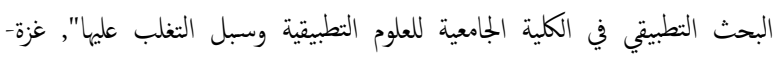

فلسطين. 2. انطوان، زملان (1997), حالة العلم والثقانة في المة العربية، مركز دارسات الوحدة

$$
\text { العربية، بيروت. }
$$

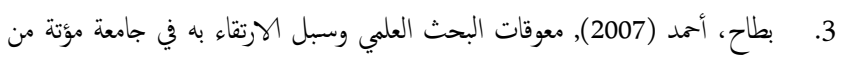

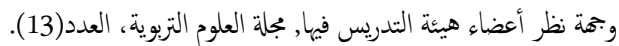

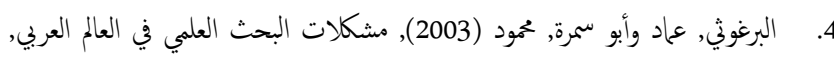

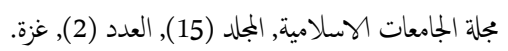

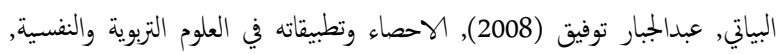
ط1, دار اثراء للنشر والتوزيع, عمان- الأردن.

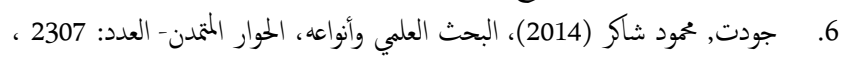

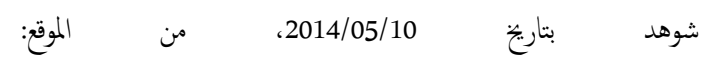
http://www.ahewar.org/debat/show.art.asp?aid=137295 7. مد، محمد حرب (1998), الإدارة الجامعية، ط1، دار اليازوري العلمية للنشر

$$
\text { والتوزيع، عمان- الهردن. }
$$

8.

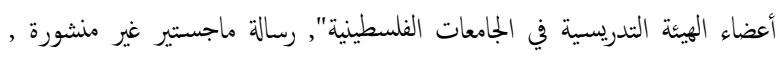

$$
\text { جامعة النجاح, فلسطين. }
$$

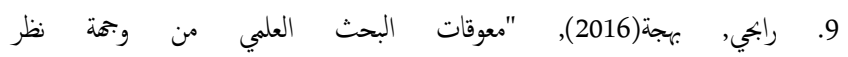
أساتذة كلية العلوم الإنسانية والاجتماعية", رسالة ماجستير منشورة, جامعة محمد

$$
\text { بوضياف المسيلة, الجزائر. }
$$

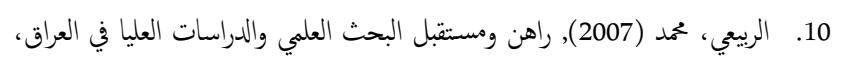
مقالة منشورة على شبكة المعلومات الدولية. 11. الريماوي، عمر وكزدي، فؤاد (2015), معوقات البحث العلمي من وبحة نظر اعضاء الهيئة التدريسية في الكليات الانسانية بجامعة القدس، مجلة كلية التربية الاساسية للعلوم التزبوية والانسانية، جامعة بابل، العدد( 20).

\begin{tabular}{|c|c|c|c|c|c|c|}
\hline \multirow{2}{*}{$\begin{array}{r}\text { الدلالة } \\
0.05 \\
0.05\end{array}$} & & القيمة الثائيا & \multirow{2}{*}{ المعياري } & \multirow{2}{*}{ الالمسابي } & \multirow[t]{2}{*}{ العدد } & \multirow{2}{*}{ اللقب } \\
\hline & الجدولية & المحسوبة & & & & \\
\hline غير دالة & 2.021 & 0.287 & 23.451 & 70.664 & 25 & مدرس \\
\hline احصائيًا & & & 20.848 & 68.864 & 25 & مساعد \\
\hline
\end{tabular}

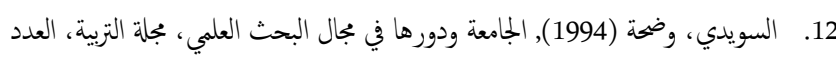
(11) 13. الشريف مصطفي (2014), "واقع البحث العلمي في ليبيا ومتطلبات التطوير. بحث

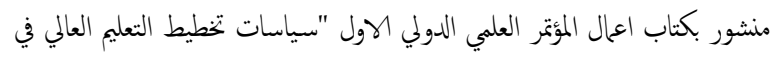
ليبيا" كلية الاقتصاد- صرمان- جامعة الزاوية.
يتضح من الجدول (4) بأن القيمة التائية المحسوبة والبالغة (0.287) أقل من القيمة الثائية الجدولية والبالغة (2.021) وهذا يعني عدم وجود فرق ذو دلالة احصائية عند مستوى (0.05) بين وبجتي نظر تدريسي كلية العلوم (مدرس, استاذ مساعد) افراد عينة البحث في المعوقات التي توابحهم أثناء كنابة وتطبيق بحوثه العلمية. وتعزي الباحثة هذه النتيجة إلى ان تدريسي كلية العلوم (مدرس, استاذ مساعد) أفراد عينة البحث يدركون واقع ما يوابحه البحث العلمي التطبيقي من معوقات, حيث انهم يقعون في ظروف مشابة من حيث المعوقات التي توابهمه, ونظرة المدرس نفس نظرة الاستاذ المساعد إلى المعوقات او الصعوبات التي تواجتهم أثناء كتابة وتطبيق بحوثهم العلمية, ولا أثر لاختلاف لقبهم العلمي على وبجات نظرهم. 5. 5 الوستنتاجات

وجود معوقات تحول دون قيام تدريسي كلية العلوم (مدرس- استاذ

$$
\text { مساعد) بالبحث العلمي النطبيقي. }
$$

يوجد تقارب بين وبهتي نظر مدرس واستاذ مساعد في المعوقات التي

$$
\text { توابجهم أثناء كنابة وتطبيق بحوثهم العلمي. }
$$

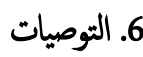

توفير الدع المادي والمعنوي لتدريسي كلية العلوم وباقي الكليات الوخرى

$$
\text { لتفعيل حركة البحث العلمي التطبيقي في الجامعة. }
$$

تشجيع الباحثين والأبحاث بالمنح والجوائز العلمية التي تعمل من أجل تعزيز

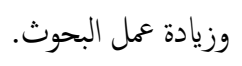

توفير ميزانية خاصة للبحث العلمي التطبيقي وتسهيل التسويات المالية والإجراءات الإدارية لإجراء البحوث العلمية التطبيقية. توفير الأجززة العلمية المتطورة والكنب والدوريات والأبحاث في المراكز

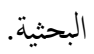




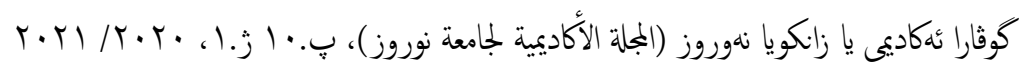

33. ناجي، عبد النور (2011), منهجية البحث السياسي، دار اليازوري العلمية للنشر والتوزيع، عان- الاردن.

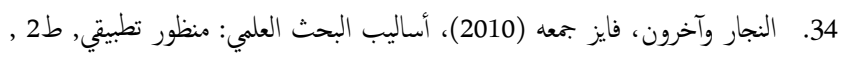
دار الحامد للنشر والتوزيع, عان - الاردن.

35. ن نحان, منصور والتمري، غسان ذيب (1998)، البحث العلمي حرفة وفن، الأردن: دار الكندي للنشر والتوزيع، عان- الاردن.

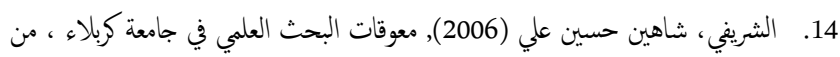
وبجة نظر التدريسيين فيها وسبل تذليلها، دراسة ميدانية, بحلة جامعة كربلاء العلمية,

الجملد (4), العدد (2).

15. الشتصي، عبداله (2006), "البحث العلمي ومعيقاته بؤوسسات التعليم العالي في

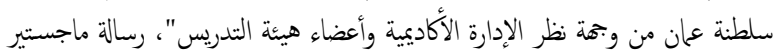
غير منشورة, الجامعة الاردنية، الاردن. 16. عباس، جال امد (2005)، واقع البحث العلي، معوقاته والملول المقترحة لتطويره،

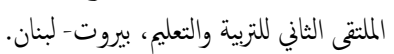

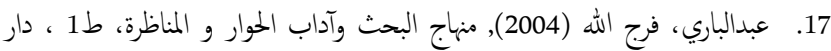
الافاق العربية، القاهرة- مصر.

18. عبيدات، ذوقان وعدس, عبد الرمن (1999), البحث العلمي (منهومه وادواته

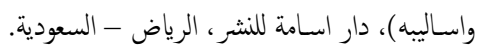

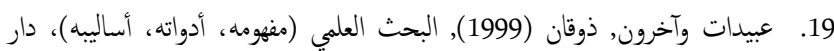
أسامة للنشر والتوزيع, الرياض - السعودية. 20. العجيلي, صباح حسين والففلي, هناء حسين (1988), معوقات البحث التردية التربوي

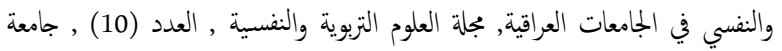
بغداد. 21. العلي وآخرون، عبد الستار (2009), المدخل الى إدارة المعرفة، ط2 ،دار المسيرة اللنشر والتوزيع للطباعة، عان- الاردن.

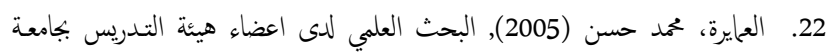

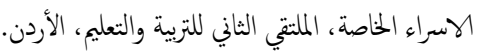

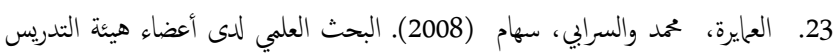

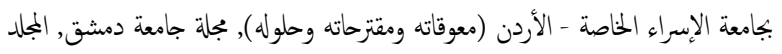
(24) (24) العدد (2). 24. الفتلي, حسين هاشم (2008) المعوقات التي تواجه الباحث في الجامعات العراقية , مجلة

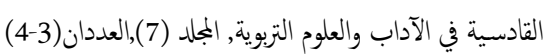

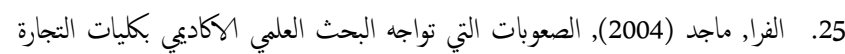
بمهافظات غزة من وبهة نظر أعضاء هيئة التدريس فيها, مجلة الجامعات الكسلامية, المجلد (12), العدد (1).

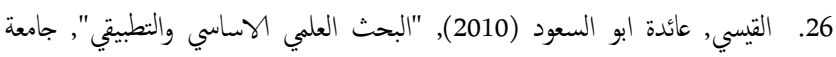
النجاح الوطنية - كلية التمريض.

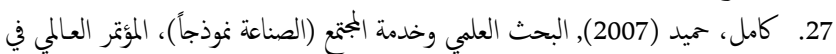
العراق. 28. لال، زكريا يحي (2000), دور البحث العلمي في مؤسسات التعليم العالي من وبحة

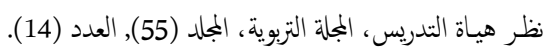

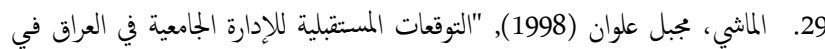

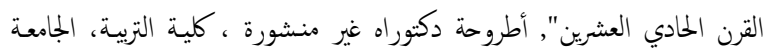
المستنصرية. - المبري 30. الجيدل، عبداله وشهاس، سالم مستييل (2010), معوقات البحث العلمي في كليات التربية من وبجة نظر أعضاء هيئة التدريس (دراسة ميدانية كلية الزببية بصلالة انموذجا), مجلة جامعة دمشق ، المجلد (26), العدد (الاول والثاني).

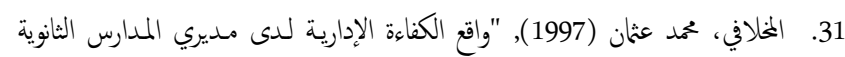
الأكاديمية في اليمن"، رسالة ماجستير غير منشورة, الجامعة الأردنية، عمان - الماردن.

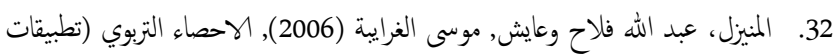

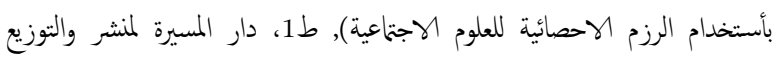

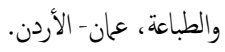

